\title{
Article \\ Experimental Investigation of Polymer-Coated Silica Nanoparticles for EOR under Harsh Reservoir Conditions of High Temperature and Salinity
}

\author{
Alberto Bila ${ }^{1,2, *}$ and Ole Torsæter ${ }^{3}(\mathbb{C}$ \\ 1 Department of Chemical Engineering, Faculty of Engineering, Eduardo Mondlane University (EMU), \\ Av. Moç. km 1.5, Maputo CP. 257, Mozambique \\ 2 Centre of Studies in Oil and Gas Engineering and Technology, Eduardo Mondlane University (EMU), \\ Av. Moç. km 1.5, Maputo CP. 257, Mozambique \\ 3 PoreLab Research Centre, Department of Geoscience and Petroleum, Norwegian University of Science and \\ Technology (NTNU), S. P. Andersens veg 15a, 7031 Trondheim, Norway; ole.torsater@ntnu.no \\ * Correspondence: alberto.bila@uemep.uem.mz
}

Citation: Bila, A.; Torsæter, O. Experimental Investigation of Polymer-Coated Silica Nanoparticles for EOR under Harsh Reservoir Conditions of High Temperature and Salinity. Nanomaterials 2021, 11, 765. https://doi.org/10.3390/nano11030765

Academic Editor: Fabien Grasset and Henrich Frielinghaus

Received: 29 January 2021

Accepted: 5 March 2021

Published: 18 March 2021

Publisher's Note: MDPI stays neutral with regard to jurisdictional claims in published maps and institutional affiliations.

Copyright: (c) 2021 by the authors. Licensee MDPI, Basel, Switzerland. This article is an open access article distributed under the terms and conditions of the Creative Commons Attribution (CC BY) license (https:// creativecommons.org/licenses/by/ $4.0 /)$.

\begin{abstract}
Laboratory experiments have shown higher oil recovery with nanoparticle (NPs) flooding. Accordingly, many studies have investigated the nanoparticle-aided sweep efficiency of the injection fluid. The change in wettability and the reduction of the interfacial tension (IFT) are the two most proposed enhanced oil recovery (EOR) mechanisms of nanoparticles. Nevertheless, gaps still exist in terms of understanding the interactions induced by NPs that pave way for the mobilization of oil. This work investigated four types of polymer-coated silica NPs for oil recovery under harsh reservoir conditions of high temperature $\left(60^{\circ} \mathrm{C}\right)$ and salinity $(38,380 \mathrm{ppm})$. Flooding experiments were conducted on neutral-wet core plugs in tertiary recovery mode. Nanoparticles were diluted to $0.1 \mathrm{wt} . \%$ concentration with seawater. The nano-aided sweep efficiency was studied via IFT and imbibition tests, and by examining the displacement pressure behavior. Flooding tests indicated incremental oil recovery between 1.51 and $6.13 \%$ of the original oil in place (OOIP). The oil sweep efficiency was affected by the reduction in core's permeability induced by the aggregation/agglomeration of NPs in the pores. Different types of mechanisms, such as reduction in IFT, generation of in-situ emulsion, microscopic flow diversion and alteration of wettability, together, can explain the nano-EOR effect. However, it was found that the change in the rock wettability to more water-wet condition seemed to govern the sweeping efficiency. These experimental results are valuable addition to the data bank on the application of novel NPs injection in porous media and aid to understand the EOR mechanisms associated with the application of polymer-coated silica nanoparticles.
\end{abstract}

Keywords: polymer-coated nanoparticles; core flood; EOR; interfacial tension; wettability alteration; nanoparticle-stabilized emulsion and flow diversion

\section{Introduction}

Water flooding is the most widely used secondary fluid injection process into an oil-bearing formation, after primary depletion, to improve oil recovery potential. Water is pumped from injection wells, sweeping the oil in the reservoir pores, to the production wells. In this course, water preferentially channels and flows through the high-permeability zones, leaving behind a significant amount of displaceable oil in low permeability-bypassed zones of the reservoir. The reservoir conformance problems manifest themselves or arise due to the contrasts in reservoir fluid properties, heterogeneity of reservoir permeability, fluid mobility contrast, etc. [1]. Moreover, during the productive life of an oilfield, these problems cause the oil to be easily trapped by capillary forces and/or bypassed by the oil recovery-drive fluid, resulting in excessive production of water and, therefore, resulting in poor sweep efficiency. The conformance problems, coupled with the scarcity of new oil 
field discoveries are the most pressing reasons for the emergence of new oil recovery technologies, aiming to (i) extract about $50 \%$ of the original oil in place (OOIP) that is left in the reservoir after primary and secondary recovery stages [2], (ii) increase oil production rates from existing fields, and (iii) fill the gap between energy supply and demand worldwide.

Nanotechnology has shown great potential to solve some of the above problems and increase profitability for the oil and gas companies. The building block of nanotechnology is the nanoparticle and it operates at the nanoscale. Nanoparticles (NPs) are defined as a collection of atoms bonded together with diameter size in the range of 1 to $100 \mathrm{~nm}$ [3]. Figure 1 illustrate a nanoparticle, it is composed of a core, the inner material, and the shell, the outer layer. The core determines the properties of a NP, whereas the shell provides a protective membrane and determines the solubility or binding affinity of the NPs with other materials [4]. For oil recovery applications, NP is designed to be wetted by both phases, thus be partly hydrophilic and partly hydrophobic [5]; together with the small size and the large surface area, NPs can have a profound displacement effect on the oil recovery-drive fluid.
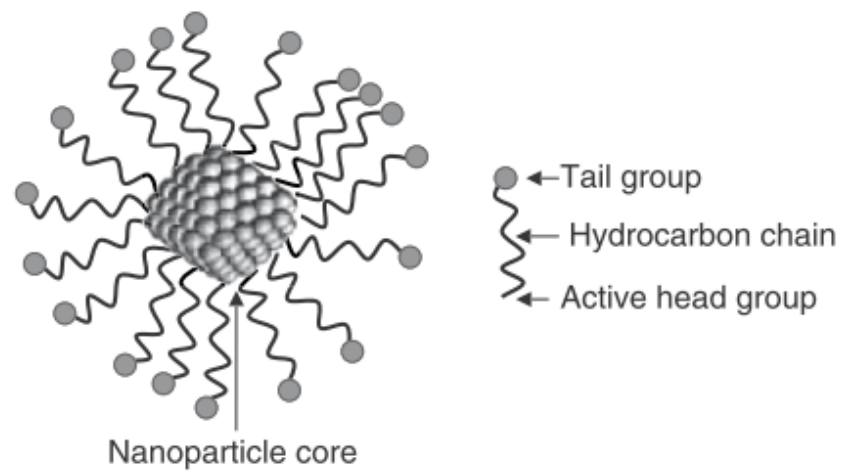

Figure 1. Schematic of a nanoparticle, showing the core and the shell [4].

The small particle size confers excellent mobility properties; hence, NPs can propagate deeply in the reservoir and increase oil recovery from thief zones and/or from bypassed zones with little retention. With small size, NPs have a large surface area and thus, a large contact area in the swept areas [6] and improved chemical reactivity properties. Therefore, NPs are suitable candidates for changing the reservoir rock and fluid properties and aid in the sweep efficiency of the injected fluid. In order to be successful for EOR applications, nanoparticles must (i) be stable in high salinity, high temperature, and high pressure reservoirs, (ii) propagate long distance between the injection and production wells with little retention, (iii) adsorb on the desired critical sites of the reservoir, such as the oil/water and fluid/rock interfaces, and (iv) prevent over-deposition on the pores [7].

One approach to achieving the above conditions and tailor the properties of NPs to improve their sweep efficiency, especially in harsh reservoir environments, is to covalently attach polymer molecules to the surface of the nanoparticles. The resulting novel polymer-coated NPs have received a wide interest in the oil and gas industry due to their improved solubility and stability, greater stabilization of emulsions and improved mobility through porous media [8,9]. Few studies have reported such characteristics for oil recovery. Rodriguez et al. [10] and Zhang et al. [11] reported that $\mathrm{SiO}_{2} \mathrm{NPs}_{\text {coated with }}$ polymer molecules have a remarkable transport behaviour through reservoir pores of various permeability with little retention due to their reversible adsorption on the rock surface. Ponnapati et al. [12] experimentally found that polymer (Poly-(oligo(ethylen oxide) monomethyl ether methacrylate)-modified $\mathrm{SiO}_{2} \mathrm{NPs}$ could mobilise residual oil and yield $7.9 \%$ of the OOIP. Behzadi and Mohammadi [13] argues that polymer-coated silica NPs can modulate oil/water interfacial tension and change the wettability of an oil-wet glass micromodel to a more water-wet state, which can confer a greater EOR effect than unmodified silica nanoparticles. Choi et al. [14] reported that grafting polymer shell layers 
on the surface of silica NP can improve stability in harsh reservoir conditions. Their core flooding tests could achieve $74.1 \%$ of the OOIP with the modified NPs, which was quite comparable to plain water flood $(68.9 \%)$ and unmodified silica NP. The authors associated the EOR effect to the NPs' ability to decrease the injection pressure; the authors argued that displacement pressure decrease is related to the formation of a wedge film between the oil and the rock surface. More recently, Bila et al. [15,16], Bila and Torsæter [17] carried out a series of flooding experiments with polymer-coated $\mathrm{SiO}_{2} \mathrm{NPs}$ in Berea sandstone core plugs. Their studies revealed an incremental recovery ranging from $2.6 \%$ to $14 \%$ of the OOIP. The authors found that the displacement efficiency of polymer-coated $\mathrm{SiO}_{2} \mathrm{NPs}_{\mathrm{s}}$ better in water-wet cores than that achieved with induced neutral-wet core plugs.

In summary, the application of NPs, at laboratory scale, have shown an incremental recovery of oil ranging from 5 to $15 \%$ of the OOIP [3], the highest reach is $32 \%$ of the OOIP $[18,19]$. The most frequent range has been $5 \%$ of the OOIP [20]. Obviously, oil recovery by NPs is a complex phenomenon, partly because the reservoirs are unique and have different characteristics. On the other hand, the variability of experimental approaches in assessing the efficiency of nanoparticle recovery ends up with variable results and variable interpretation of the causes of oil displacement.

Following the encouraging results, studies have demonstrated marvellous efforts to understand the EOR mechanisms of nanofluid flooding. The change in reservoir wettability and the reduction of the interfacial tension are the two well accepted mechanisms of NPs [20,21]. Nanoparticles can alter the reservoir's wettability by (i) adsorbing on the reservoir rock to develop a new surface roughness [22,23], destabilizing oil films and desorbing it from the surface, and (ii) applying the structural disjoining pressure mechanism [24]. The adsorption of charged NPs can change the reservoir's wetting properties by forming hydrogen bonds with water molecules, there on attracting water molecules to the surface while lifting oil from it $[18,25]$. Further, the adsorption of NPs can reduce the interfacial energy between the rock surface and the oil, which disrupts whatever molecular attachment amongst the rock surface and the oil molecules attached to the surface [25]. Nanoparticles can also adsorb onto oil/water interface and decrease the interfacial tension between the two phases. For this, the NPs form a mono-layer that replaces the existing oil/water interface, acting as a mechanical barrier and bring the two phases together [26]. Moreover, depending on the hydrophobicity nature of NPs, they can irreversibly adsorb to the oil/water interface. There, the formed denser layer of NPs can protect oil droplets from flocculation and coalescence via steric mechanism to result in the stabilization of emulsion droplets by nanoparticles $[9,27]$. These emulsions (Pickering emulsions) can travel through the pores of the reservoirs with minimal retention and increase oil recovery [27].

Aside from the above mentioned mechanisms, NPs can block reservoir pore-throats larger than their size and increase oil recovery via log jamming mechanism [28,29]. Nanoparticles can increase the viscosity of EOR fluid and reduce the viscosity of the heavy oil, which can be reflected in a favourable mobility of the displacing and displaced phases, respectively, for oil recovery.

This work aims to expand our previous works $[15,16]$ and attempts to investigate the recovery mechanisms of polymer-coated silica NPs under harsh reservoir conditions of high temperature and salinity. The goal is to provide additional experimental results to the data bank on the nanoparticles for enhanced oil recovery projects, while paving the way to improve our understanding of the underlying EOR mechanisms associated with silica nanoparticles.

\section{Experimental Materials and Methods}

\subsection{Nanoparticles and "Simulated" Seawater}

Nanostructured products from Evonik Industries AG were used for oil recovery experiments in this work. The nanostructured materials were supplied as special research and development (R\&D) laboratory products, hereafter simply referred to as nanoparticles. They were supplied to us in small containers as AERODISP ${ }^{\circledR}$, which is AEROSIL ${ }^{\circledR}$ particles 
in liquid solution as shown in Figure 2. They are spherical and amorphous products mainly composed of silicon dioxide $\left(\mathrm{SiO}_{2}>98.3 \%\right)$; additional components are aluminium oxide $\left(\mathrm{Al}_{2} \mathrm{O}_{3}\right)$ and mixed oxides (MOX). The surface of NPs were coated with Poly (methacrylate) based molecules to improve dispersion stability and lower the hydrophilicity nature that characterizes typical silica materials to form polymer-coated/functionalized nanoparticles. Properties of the particles are given in Table 1. The size of the nanoparticles was measured using the dynamic light scattering technique.

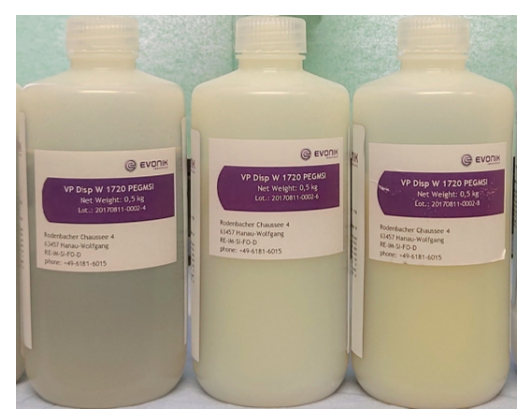

Figure 2. Concentrated aqueous solutions of silica nanoparticles.

Table 1. Properties of the aqueous solutions of silica nanoparticles.

\begin{tabular}{llcccc}
\hline Sample & Basis & Modification & Conc., wt. $\%$ & Size $_{(\mathbf{n m})} \mathbf{a}^{\mathbf{a}}$ & Size $^{(\mathbf{n m})^{\mathbf{b}}}$ \\
\hline NF-A & $\mathrm{SiO}_{2}$ (sol-gel-cationic) & Polymer & 38.6 & 107 & 63 \\
NF-B & $\mathrm{SiO}_{2}$ (sol-gel-anionic) & Polymer & 26.0 & 32 & 38 \\
NF-C & $\mathrm{SiO}_{2} / \mathrm{Al}_{2} \mathrm{O}_{3} / \mathrm{MOX}$ & Polymer & 21.6 & 218 & 155 \\
NF-D & $\mathrm{SiO}_{2} / \mathrm{Al}_{2} \mathrm{O}_{3} / \mathrm{MOX}$ & Polymer & 25.5 & 145 & 135 \\
\hline
\end{tabular}

a Average particle size in concentrated solutions (as received). ${ }^{\mathrm{b}}$ Average particle size measured with NPs diluted to 0.1 wt. $\%$ with simulated seawater.

The simulated seawater was prepared with ions typical of sea water $\left(\mathrm{Na}^{+}, \mathrm{Ca}^{2+}, \mathrm{Mg}^{2+}\right.$, $\mathrm{SO}_{4}{ }^{2+}, \mathrm{K}^{+}$, etc.), by mixing salts with distilled water, following the homogenization process. The total of dissolved salts was $38,318 \mathrm{ppm}$. For oil recovery experiments, the concentrated solutions of nanoparticles were diluted to $0.1 \mathrm{wt} . \%$ concentration with simulated seawater. The resulting nanofluid solutions were stirred using a magnetic stirrer for at least $30 \mathrm{~min}$ to prevent aggregation/agglomeration of particles. The properties of water and nanofluids are given in Table 2, and were measured in our previous work [16]. The density and viscosity were measured at $60{ }^{\circ} \mathrm{C}$ with an Anton Paar density meter DMA ${ }^{\mathrm{TM}} 4100 \mathrm{M}$ series and Anton Paar Rheometer, respectively. The $\mathrm{pH}$ of the solutions was measured by a $\mathrm{pH}$ Meter (model pH $1000 \mathrm{~L}$, phenomenal ${ }^{\circledR}$ ).

Table 2. Fluid properties measured at $60^{\circ} \mathrm{C}$.

\begin{tabular}{cccc}
\hline Fluid & Density $\left(\mathbf{g} / \mathrm{cm}^{3}\right)$ & Viscosity $(\mathbf{c P})$ & $\mathbf{p H}$ \\
\hline Seawater & 1.008 & 0.53 & 7.97 \\
Nanofluids & $1.007-1.009$ & $0.51-0.67$ & $7.74-8.05$ \\
\hline
\end{tabular}

\subsection{Non-Wetting Phase}

Crude oil obtained from a field in the North Sea was used as the non-wetting phase, it had a viscosity of $6 \mathrm{cP}$ and $33^{\circ} \mathrm{API}$ gravity at at $60^{\circ} \mathrm{C}$. The crude oil SARA (Saturates, Aromatics, Resins, Asphaltenes) analysis is provided in Table 3. It is classified as a light oil with asphaltenes content of $0.18 \mathrm{wt} . \%$. It was filtered twice through a $5 \mu \mathrm{m}$ Millipore to remove suspended particles and preserve original composition. The density and viscosity were measured with the same instruments used in Section 2.1. Normal decane with density and viscosity of $0.73 \mathrm{~g} / \mathrm{cm}^{3}$ and $0.92 \mathrm{cP}$ at $20{ }^{\circ} \mathrm{C}$, respectively, was used in the wettability experiments. 
Table 3. Properties of the crude oil.

\begin{tabular}{lll}
\hline Property & Value & Unit \\
\hline Saturates & 71.57 & $\mathrm{wt} . \%$ \\
Aromates & 20.81 & $\mathrm{wt} \%$ \\
Resins & 7.44 & $\mathrm{wt} \%$ \\
Asphaltenes & 0.18 & $\mathrm{wt} \%$ \\
Density at $60^{\circ} \mathrm{C}$ & 0.87 & $\mathrm{~g} / \mathrm{cm}^{3}$ \\
Viscosity at $60^{\circ} \mathrm{C}$ & 6.0 & $\mathrm{cP}$ \\
API gravity & 33 & $\mathrm{deg}$ \\
\hline
\end{tabular}

\subsection{Preparation of Porous Medium}

Eight core plugs were drilled from Berea sandstone block and prepared to have similar diameter $(3.75 \mathrm{~cm})$ and length $(10 \mathrm{~cm})$. The bulk mineral composition was measured using X-ray diffraction (XRD) on five core plugs. All samples were composed of 93.7 vol \% quartz, $5 \mathrm{vol} \%$ of Microcline (Alkali feldspar) and $1.3 \mathrm{vol} \%$ Diopside. They are classified as homogeneous and strongly water-wet rocks. The cores were cleaned with methanol using Soxhlet extractor and dried at $60{ }^{\circ} \mathrm{C}$ for $\approx 3$ days. Porosity was measured by imbibition method and permeability by Darcy's law using a constant head permeameter, flowing nitrogen gas through the core. The gas permeability obtained was then corrected for the Klinkenberg effect to reflect the liquid's permeability. The core properties are given in Table 4.

Table 4. Properties of the rock core plugs.

\begin{tabular}{ccccc}
\hline Core & Porosity, (\%) & Permeability, $\mathbf{m D}$ & Pore Volume, $\mathbf{~ m L}$ & $\mathbf{S}_{\boldsymbol{w i} \boldsymbol{i}} \mathbf{( \% )}$ \\
\hline H1 & 17.61 & 332 & 19.25 & 24.66 \\
H2 & 19.55 & 384 & 19.06 & 21.32 \\
H3 & 17.40 & 361 & 19.22 & 16.24 \\
H4 & 17.56 & 434 & 19.39 & 16.45 \\
H5 & 16.70 & 460 & 19.83 & 17.81 \\
H6 & 17.16 & 411 & 19.10 & 15.00 \\
H7 & 17.61 & 425 & 19.25 & 14.00 \\
H8 & 19.42 & 377 & 18.78 & 19.60 \\
\hline
\end{tabular}

The cleaned and dried core plugs were saturated with reservoir simulated formation water using a vacuum pump with a chamber pressure set at $100 \mathrm{mbar}$ for three hours. Then, the core plugs were soaked in the same water for at least 10 days to attain ionic equilibrium with the rock constituents.

Primary drainage was conducted by injecting crude oil into the cores to displace the water and set initial water saturation $\left(S_{w i}\right)$. Next, the cores with $S_{w i}$ were submerged in metallic containers filled with the same crude oil used to displace the water and soaked for seven months at $80{ }^{\circ} \mathrm{C}$. The aim was to decrease the water wetness in the cores. The aging time and the high temperature can break the water films on the surface, facilitating the adsorption of polar components of crude oil to change the rock wettability. The results of the aging process are presented in Section 3.2.4 and show that wettability of the cores has been changed from a strongly water-wet surface to a neutral-wet state.

\subsection{Displacement Tests}

Oil displacement tests were carried out at the reservoir temperature $\left(60^{\circ} \mathrm{C}\right)$ in aged core plugs to determine the EOR potential of silica based nanofluids. A schematic of the core flooding apparatus is shown in Figure 3. It is comprised of an injection pump, three tanks each containing crude oil, water and nanofluid. The reservoir tanks were assembled vertically inside an oven set at $60{ }^{\circ} \mathrm{C}$. A check valve and back pressure regulator (set to 5 bars) were used to prevent any back flow of produced fluids and keep the system pressure constant during the experiments. The core was loaded in the Hassler core-holder and 
oriented horizontally under confining pressure held within 18-22 bars. The crude oil was injected at low rate $(0.02 \mathrm{~mL} / \mathrm{min})$ to eliminate any air bubbles, until the temperature in the reservoir stabilized at $60^{\circ} \mathrm{C}$. To simulate oil production of a reservoir: (i) conventional water-flood was conducted at a constant reservoir flow rate, $0.2 \mathrm{~mL} / \mathrm{min}$, until there was no oil production for 1-pore volumes (PVs). Next, the flowrate was increased ten-fold (bump flood) for 1-PV in order to mitigate capillary end-effects, establish water flood residual oil saturation and ensure that any production would result from the injection of nanofluid. (ii) the injection was continued with nanofluids at the constant flow rate until there was no more oil production at core outlet for $\approx 3$-PVs; likewise, the bump flood was applied for 1-PV. To study the behaviour of the injection fluid flow through the pores, two pressure sensors were connected at the entrance and exit of the core-holder; the differential pressure of the fluid across the core was recorded using a computer.

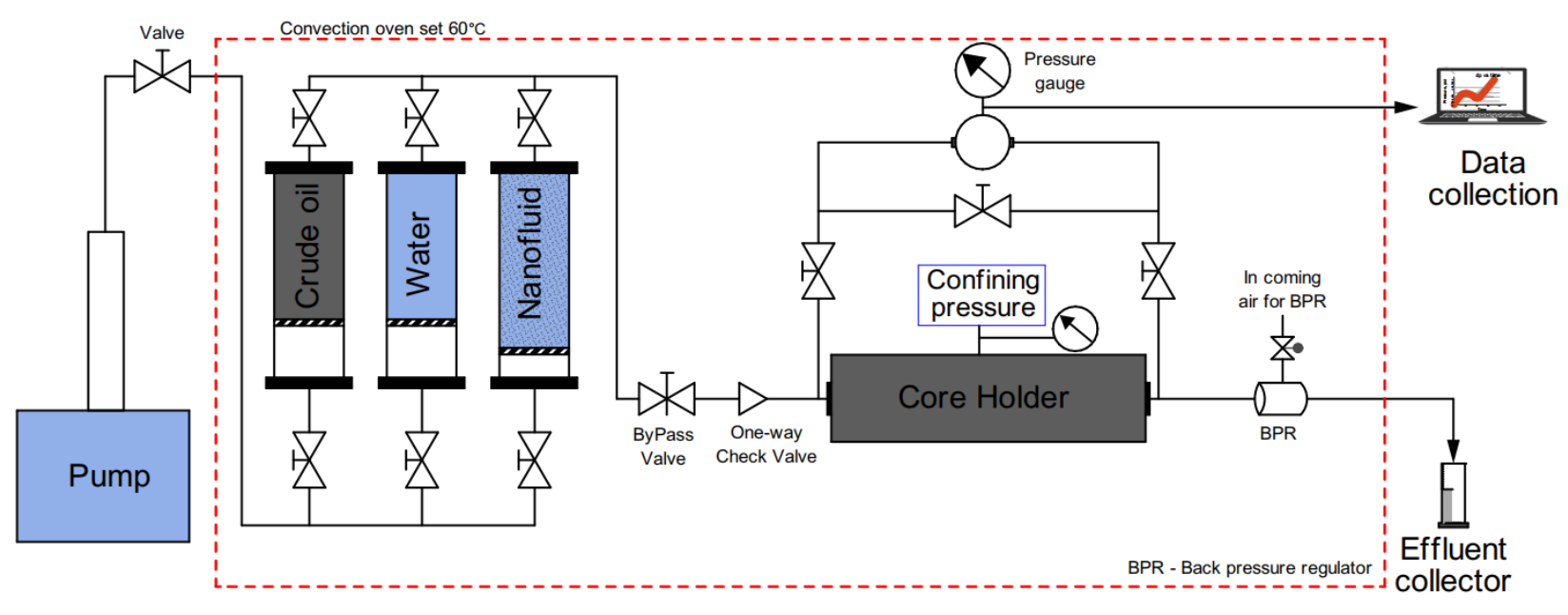

Figure 3. Schematic diagram of core flooding experiment.

\subsection{Interfacial Tension Measurement}

Interfacial tension (IFT) is the most important property that characterises the interface of two immiscible or partially miscible fluids that are in contact. Accordingly, it influences the extraction of crude oil from reservoir pore spaces. Interfacial tension can be measured by a variety of methods. A spinning drop method, SVT20N (Data Physics) video tensiometer, was used in this work. The crude oil was injected drop-wise into a capillary tube filled with water or nanofluid. Then, the apparatus was set a $60^{\circ} \mathrm{C}$ and the tube rotated at a speed held within 6000-8000 rpm until the equilibrium was reached; then, the static IFT value was read off. The average refractive index of the continuous phases was 1.338.

\subsection{Spontaneous Imbibition Tests}

The spontaneous imbibition (SI) tests provide a qualitative measure of the ability of the wetting-phase to displace the non-wetting phase under static conditions [30]. Generally, the SI tests are performed in visual glass with graduated tube on top called Amott cell. An oil-saturated core plug $\left(a t S_{w i}\right.$ ) is place in the cell filled with water. Free-oil displacement by water is expected to take place over a period of time. The produced oil is collected on the top of graduated tube until equilibrium is reached. The dynamic imbibition is established as cumulative oil production versus time to interpret the change in wettability. In this work, the Amott water index $\left(\mathrm{I}_{w}\right)$ was also calculated to validate SI tests. At equilibrium, the volume of oil produced by $\mathrm{SI}$ is $\mathrm{V}_{01}$. The remaining oil in the core was forcibly displaced by injecting water; the produced oil is $\mathrm{V}_{02}$. The Amott water index is calculated as: $\mathrm{I}_{w}=\mathrm{V}_{o_{1}} /\left(\mathrm{V}_{o_{1}}+V_{o_{2}}\right)$. The closer to 1.0 the $\mathrm{I}_{w}$ is, the strongly water-wet the rock system is; smaller values of $\mathrm{I}_{w}$ indicate less water-wetting preference. It is worthy to mention that the core plugs were injected with decane before and after the nanofluid-EOR tests to set $S_{w i}$; then the imbibition tests were followed. This procedure aimed to study the 
wetting conditions that can be achieved after the interaction between the NPs and crude oil/water/rock system. The results are used to interpret oil displacement mechanisms of polymer-coated silica NPs.

\section{Results and Discussion}

\subsection{Nanoparticle's Oil Recovery}

Most oil reservoirs are characterised by high pressure, high temperature, high salinity and an uneven properties $[8,31,32]$. Thus, EOR technologies must be designed to operate nearly under identical conditions to provide realistic results. Presently, an attempt was made in this direction, carrying out the EOR experiments at the reservoir temperature of $60^{\circ} \mathrm{C}$, and dispersing the nanofluids in typical reservoir brine. The cores aged to less water-wet state. A bump flood was applied at the end of the low rate flood to ensure that any additional production would be a result of the nanofluid injection.

The oil recovery performance for the selected nanofluids is shown in Figure 4 . Note that each nanofluid sample was tested twice. Figure $4 a$, b show the oil displacement profiles for the nanofluids with the smallest particle size $(32 \mathrm{~nm})$ and the largest particle size $(218 \mathrm{~nm})$, respectively. The oil recovery from the water flood (WF) is given by the blue curves, sequentially for (i) low rate (continued lines), and (ii) tenfold increase in flow rate for 1 PV (dashed lines). Then, the nanofluid was injected targeting water flood residual oil saturation. Likewise, the continued and dashed lines indicate the recovery of oil during the low rate and the high rate, respectively. The water flood conducted over the aged core samples exhibited an early water breakthrough, but accompanied with prolonged periods of co-production of water and oil. This displacement behavior conferred a greater oil recovery at the end of water flood, which is an agreement with previous studies [33,34]. The recovered oil, during the bump flood stage, seemed insignificant, except for the core $\mathrm{H} 3$ with $3.73 \%$ of the OOIP. This oil production can be attributed to the capillary end-effects and/or capillary stability. When capillary stability is not guaranteed during the low-rate displacement stage, the oil can snap off and easily become trapped in the larger pores as water saturation increases in the pores. These disconnected oil drops can be easily produced by increasing the flowrate. Experimental tests suggest that the capillary end-effects are less pronounced in intermediate rock systems [15,35], such as those used in this work.

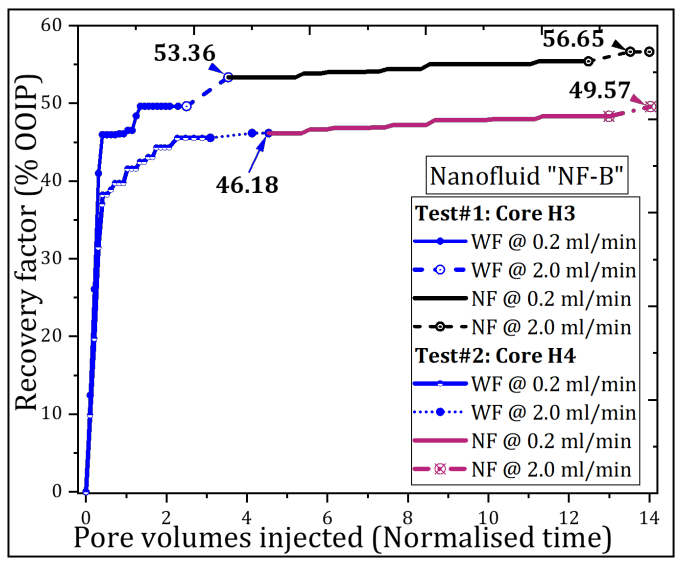

(a)

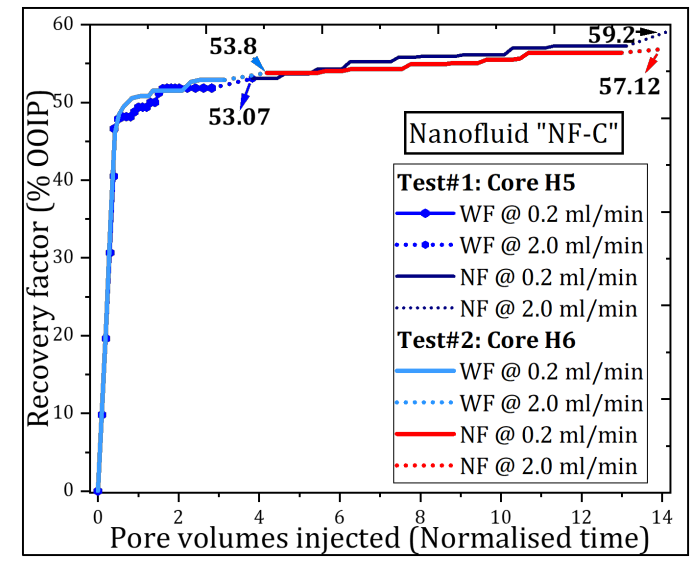

(b)

Figure 4. Effect of nanofluid injection on oil recovery during normal low rate and bump rate injections: (a) Sample NF-B: Test\#1 the first oil production occurred $\approx 1.8 \mathrm{PVs}$ and the RF $\approx 0.5 \%$ OOIP; Test\#2 produced $\approx 0.5 \%$ OOIP at $1 \mathrm{PV}$. (b) Sample NF-C: Test \#1 the oil production occurred at $\approx 2.2 \mathrm{PVs}$ and the RF $\approx 2.3 \%$ OOIP; Test \#2 the first production occurred at $\approx 1.3 \mathrm{PV}$ and the $\mathrm{RF} \approx 0.3 \%$ OOIP.

It is important to note that the current results indicate that on a laboratory scale, any EOR fluid must be performed after many pore volumes of water have been injected in the cores at low rate to achieve capillary stability and establish an adequate residual oil 
saturation. With this procedure, if the EOR fluid is successful in the laboratory, it is more likely to be successful in the field as well.

Nanofluid was injected to interact with the crude oil/rock/water system. The occurrence of oil at the exit of the core during the nanofluid injection stage was observed after 1 or 2 PVs (see Figure 4). This shows the time dependence of such interactions between the NPs and the crude oil/water/rock system towards improving the microscopic sweep efficiency of the oil-drive fluid. The interactions can be of particle adsorption type on the crude oil/water/rock interfaces. There on, the NPs can decrease the interfacial energy and change the wetting properties of the rock surface, and increase oil recovery. All results are summarised in Table 5. The average recoveries are shown in Figure 5 for comparison with the previous study. Total water flood oil recoveries varied in between $46.18 \%$ and $66.75 \%$ of the OOIP. This variation can be due to saturation profiles, pore structures, viscosity ratio and experimental errors. On average, 10-PVs of nanofluids were injected. This resulted in an incremental recovery ranging from 1.51 to $6.13 \%$ of the OOIP. The twin core plugs produced comparable recovery factors and the differences are in the margin of experimental error. The displacement efficiency $\left(E_{D}\right)$ evaluated by Equation (1) shows the effectiveness of polymer-coated silica nanofluids in mobilising water flood residual oil at pore scale under harsh reservoir conditions.

$$
E_{D}=\left[1-\left(\frac{S_{o r_{2}}}{S_{o r_{1}}}\right)\right] \times 100 \%
$$

Here, the $\mathrm{S}_{o r_{1}}$ and $\mathrm{S}_{o r_{2}}$ is the residual oil saturation after water- and nanofluid-flooding, respectively.

Table 5. Oil recovery factors (water- and nanofluid-flooding), expressed as \% of the OOIP, and residual oil saturation achieved at the end of core flooding in neutral-wet cores.

\begin{tabular}{|c|c|c|c|c|c|c|c|c|c|c|c|}
\hline \multirow[b]{2}{*}{ Core } & \multirow[b]{2}{*}{ Fluid } & \multicolumn{4}{|c|}{ Water Flood } & \multicolumn{4}{|c|}{ Nanofluid Flood } & \multirow[b]{2}{*}{$\mathbf{R F}_{t}$} & \multirow[b]{2}{*}{$\mathrm{E}_{D}(\%)$} \\
\hline & & RF1 & RF2 & RF & $\mathrm{S}_{o r_{1}}$ & RF1 & RF2 & RF & $\mathrm{S}_{o r_{2}}$ & & \\
\hline H1 & \multirow{2}{*}{ NF-A } & 59.45 & 2.90 & 62.35 & 28.37 & 2.76 & 2.07 & 4.83 & 24.47 & 67.18 & 13.74 \\
\hline $\mathrm{H} 2$ & & 57.33 & 0.67 & 58.00 & 33.05 & 1.73 & 0.00 & 1.73 & 31.68 & 59.73 & 4.13 \\
\hline H3 & \multirow{2}{*}{ NF-B } & 49.63 & 3.73 & 53.36 & 39.07 & 2.05 & 1.24 & 3.29 & 36.32 & 56.65 & 7.06 \\
\hline $\mathrm{H} 4$ & & 45.56 & 0.62 & 46.18 & 44.97 & 2.16 & 1.23 & 3.39 & 42.14 & 49.57 & 6.31 \\
\hline H5 & \multirow{2}{*}{$\mathrm{NF}-\mathrm{C}$} & 51.84 & 1.23 & 53.07 & 38.57 & 4.29 & 1.84 & 6.13 & 33.63 & 59.20 & 12.81 \\
\hline H6 & & 52.88 & 0.92 & 53.80 & 39.43 & 2.82 & 0.50 & 3.32 & 36.61 & 57.12 & 7.17 \\
\hline H7 & \multirow{2}{*}{ NF-D } & 66.45 & 0.31 & 66.75 & 28.67 & 1.20 & 0.30 & 1.51 & 27.37 & 68.25 & 4.53 \\
\hline H8 & & 53.64 & 0.80 & 54.44 & 37.27 & 3.05 & 0.93 & 3.98 & 34.08 & 58.41 & 8.57 \\
\hline
\end{tabular}

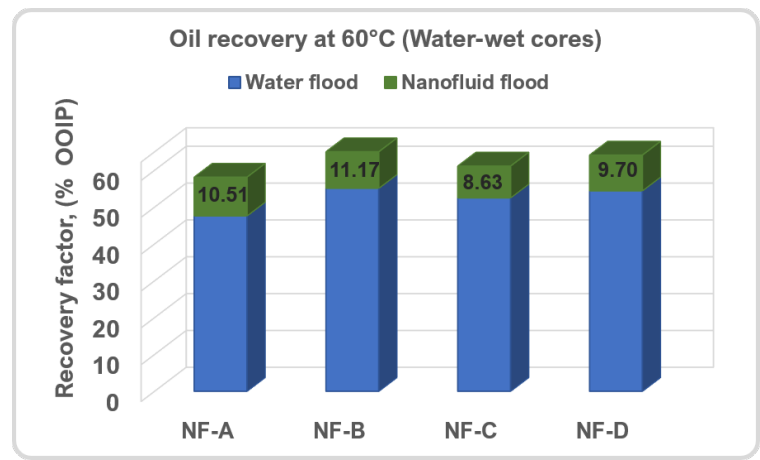

(a)

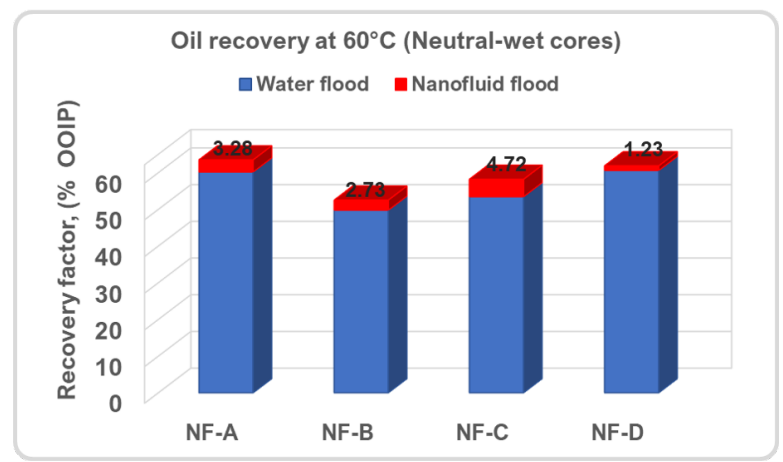

(b)

Figure 5. Comparison of average oil recoveries from various nanofluid floods: (a) Water-wet cores [16], and (b) Neutral-wet Berea core (present study). 
The temperature seemed to have minor influence on oil recovery in neutral-wet cores, unlike in water-wet cores. Figure 5 illustrates the average oil recoveries for comparison purposes obtained in water-wet and neutral-wet Berea cores conducted under similar procedure and conditions. Figure 5a shows the nanofluid flooding results in water-wet systems and were extracted from Bila et al. [16], while the current results are given by Figure $5 b$ and were calculated from Table 5. Clearly, the results indicate a superior oil recovery behaviour in water-wet Berea sandstone with the injection polymer-coated silica NPs. This may be associated with entrapping phenomenon in both rock systems during water flooding stage. In water-wet rocks, water fills the smaller pores and retains a considerable amount of the oil in the larger pores after water flooding which is amenable to EOR process. In contrast, neutral-wet cores tend to recover considerable amount of oil, despite the early water breakthrough. In addition, oil is trapped in the smallest pores and the residual oil saturation would resist mobilisation.

Aside from the temperature, the size of the nanoparticles seemed to influence the displacement efficiency; largely due to stability issues. Particularly, samples NF-C and NF-D with the largest particle size aggregated at core entrance during the EOR experiments. This resulted in physical filtration and the formation of nanoparticle "cake", shown in Figure 6. This was also observed in our previous work [16] but with water-wet Berea core plugs. However, the resultant layer of NPs appeared noticeably thicker in water-wet rocks, resulting in higher displacement pressures than in neutral-wet rock systems. This may indicate that polymer-coated NPs are more effective in improving the fluidity of the particles through neutral-wet Berea pores than in water-wet Berea pores.

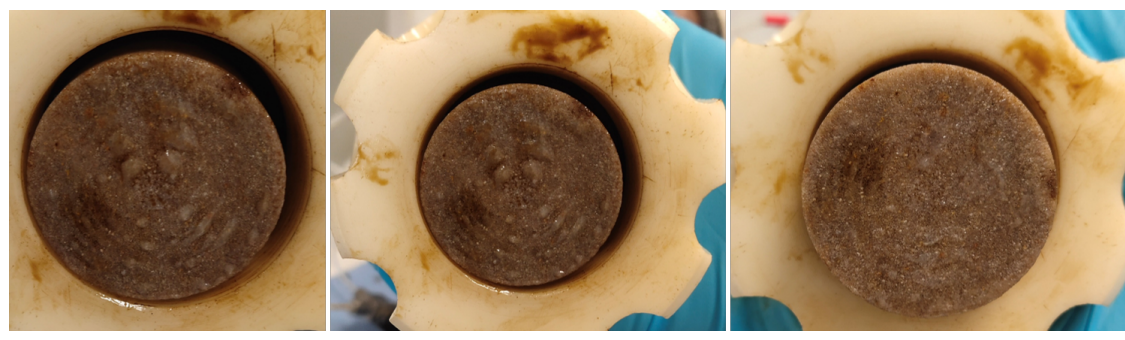

Figure 6. Physical filtration and formation of nanoparticle "cake" at core inlet during nanofluid flooding.

\subsection{Mechanisms behind EOR by Nanoparticles}

\subsubsection{Effect of Nanoparticles on Viscosity of Injection Water}

Together with interfacial tension, the viscosity provides a qualitative measure of how, and to what extent, oil will flow through porous media [36]. The research have reported tremendous increase in the viscosity of the injection fluid in the presence of NPs, which can significantly improve oil sweep efficiency. The size and concentration of the NPs are the main parameters that affect the viscosity of the injection water $[8,25]$. An increase in the viscosity of injection fluid is reflected in the mobility of adjacent fluid molecules around the nanoparticles. For instance, highly concentrated nanofluid can give a uniform displacement front $[12,25]$, which is favourable for increasing oil sweep efficiency.

In the present work, nanoparticles at $0.1 \mathrm{wt}$. $\%$ had negligible effect on the viscosity of injection seawater. The viscosity of the nanofluids varied from 0.51 to $0.67 \mathrm{cP}$ compared to $0.53 \mathrm{cP}$ of reference injection water. Hence, neither the concentration of polymers, as coating materials, nor the concentration of NPs was enough to generate a significant viscosity change in aqueous solution. The results lead to a similar conclusion to the previous study by Metin et al. [37], where low concentrations ( $\leq 5 \mathrm{wt} . \%$ ) of NPs have been shown not to affect aqueous viscosity. Therefore, we expect oil recovery to be largely influenced by factors other than viscosity. 


\subsubsection{Reduction in Interfacial Tension (IFT)}

Normally, NPs are designed to be wetted by both phases, thus being partly hydrophilic and partly hydrophobic, to allow for a better reduction in IFT [5] and decrease capillary forces. At low capillary forces, the dynamic displacement lengthens the oil droplets within the pores; then the oil drops break into smaller ones to flow within the waterbed to the production wells.

Bila et al. [16] found that IFT measurement with the Pendant drop method would not provide reliable results because, at high temperature, the polymer-coated $\mathrm{SiO}_{2} \mathrm{NPs}$ were attracted to the oil/water interface (see Figure 7a). From then on, making nanofluid solutions opaque before settlement due to gravity forces. Therefore, in this work, the IFT was obtained by analyzing the surface of the oil droplet immersed in a rotating capillary tube using a high-resolution camera and image analysis software. The use of a small volume of fluids in the capillary tube and the speed of rotation probably hindered the formation of large NP aggregates, allowing the measurement of IFT. At the equilibrium, IFT values obtained by the spinning drop method are given in Figure $7 \mathrm{~b}$ as a function NP size.

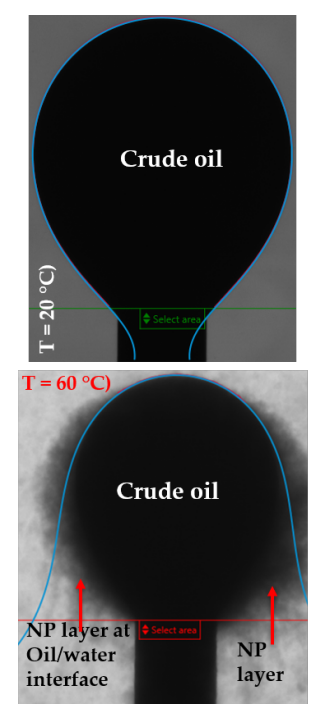

(a)

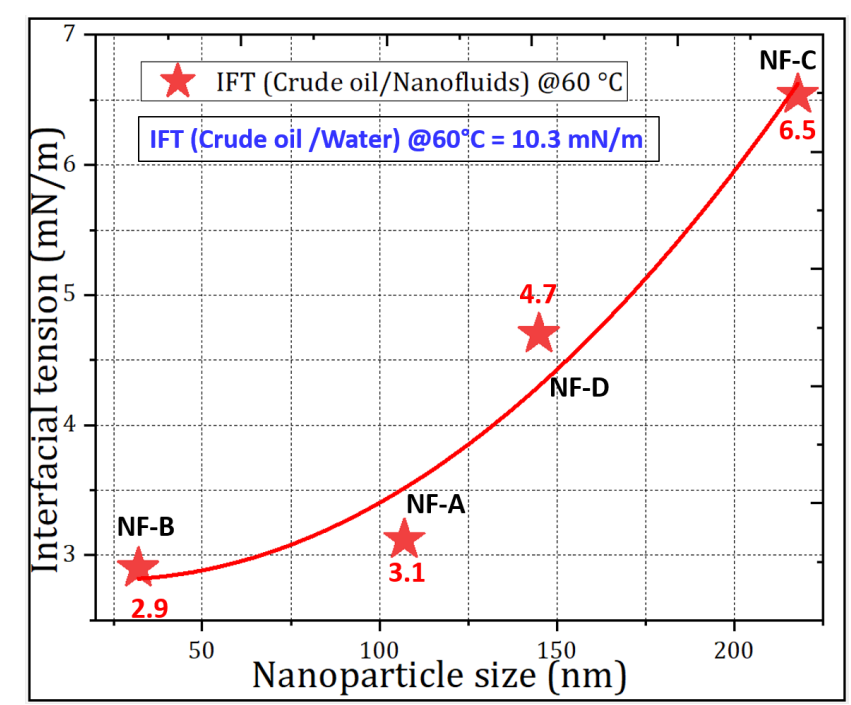

(b)

Figure 7. Dynamic measurement of the IFT between crude oil and nanofluids (0.1 wt.\%): (a) Pendant drop method: Crude oil drop on top of a J-shape syringe needle at $20^{\circ} \mathrm{C}$ (top) and at $60{ }^{\circ} \mathrm{C}$ (bottom). At $60{ }^{\circ} \mathrm{C}$, the nanoparticles self-assembled onto the oil/water interface [16]. (b) Variation of the IFT measured with Spinning drop technique $\left(\right.$ at $\left.60^{\circ} \mathrm{C}\right)$ with nanoparticle size.

The IFT between crude oil and water, at $60^{\circ} \mathrm{C}$, was $10.3 \mathrm{mN} / \mathrm{m}$ [16]; in the presence of NPs, IFT decreased to 6.5 to $2.9 \mathrm{mN} / \mathrm{m}$. Furthermore, Figure $7 \mathrm{~b}$ shows that the reduction is dependent on the size of the nanoparticles. The smallest NPs tend to exhibit a high affinity capacity to adsorb at the interface, coming into contact with a large surface area; consequently, the NPs had the largest IFT reduction compared to the larger particles. For example, the NF-B sample with the smallest size $(32 \mathrm{~nm})$ reduced the IFT by $71.8 \%$ compared to the $36.9 \%$ reduction by the largest NF-C sample. This can be associated with the increase in repulsive forces between the smallest NPs, resulting in a greater disjoining pressure between the two-phase molecules [38]. In addition, the IFT reduction can be due to the surface-active polymer molecules surrounding the surface of the NPs that provide steric repulsive forces and stabilization of the NPs suspension. Comparing the results of the IFT data from previous studies at room temperature [15,17], for the same NPs, the greatest IFT reduction is achieved at elevated temperature. This indicates that the wetting properties and the binding energy of the NPs to the oil/water interface increase with temperature. This has been attributed to the intensification of Brownian motion, which increases the 
particle collision and reduces intermolecular interactions between oil/water [26]. However, the displacement of oil at elevated temperature still has a multiple effect on IFT, the formation of aggregates/agglomerates of NPs, the loss of NPs at the interface and the inhibition of NPs from performing their designated surface functions at the interfaces and compete for poor performance of nanoparticles.

According to Sheng [39], significant oil recovery is achievable by reducing IFT to an ultra-low value of $10^{-3} \mathrm{mN} / \mathrm{m}$. However, the reduction in IFT, even below the critical value, can still play a significant role in EOR; can alter the distribution of oil in the pores [40], can contribute to the generation and stabilization of emulsions by nanoparticles [8].

\subsubsection{Formation of Emulsions Stabilized by Nanoparticles}

A reduction in interfacial tension can create favorable conditions for the generation and stabilization of emulsion during the process of oil recovery by nanofluids. This premise was studied by increasing injection flow rate at the end of low rate injection. High flow rate can provide an extra energy necessary to break up oil phase and allow for NPs to adsorb to the fluids interface [41], thus generating emulsions. The produced core flooding effluent was then visualised using a high-resolution microscopic camera; the magnified images of the flooding effluent are presented in Figure 8. The images illustrate oil drops dispersed in aqueous solution in the presence of nanoparticles, indicating that residual oil was produced as oil-in-water emulsions.

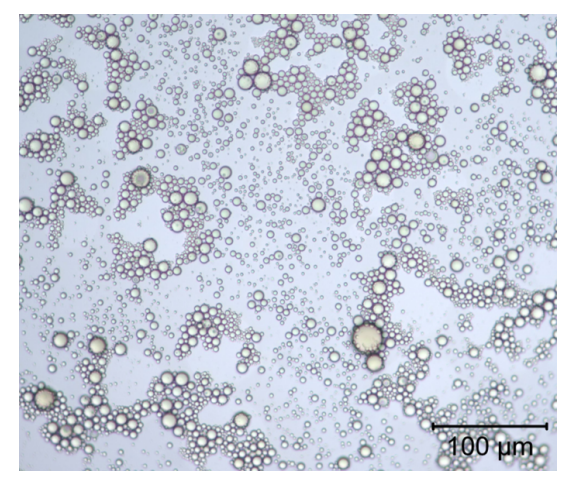

(a)

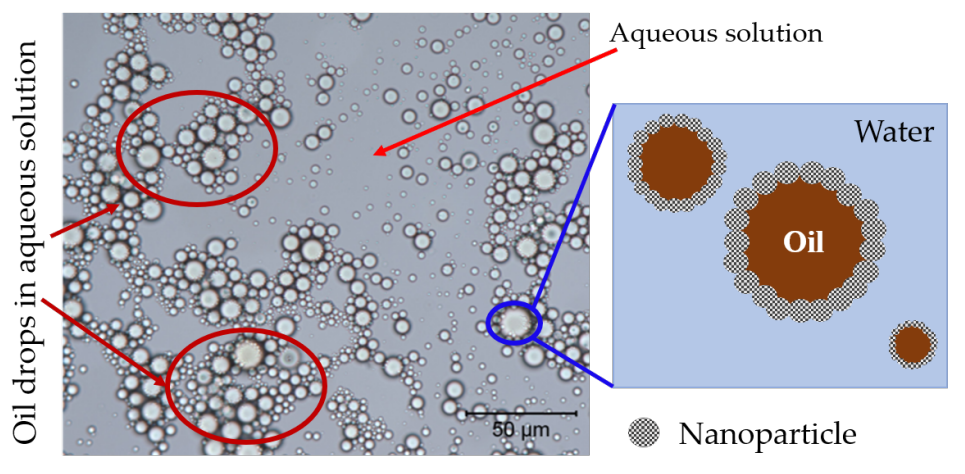

(b)

Figure 8. Visualisation of oil-in-water emulsion droplets from core flood effluent: (a) $20 \times$ magnification image, and (b) $50 \times$ magnification image.

In Figure 8, the adsorption of silica NPs seemed to create a rigid layer on the surface of the oil droplet, temporarily stabilising oil droplets against flocculation and coalescence via steric mechanism in the aqueous phase. The size distribution of the generated emulsions was not determined to compare with pore-throat sizes; however, Arab et al. [42] explain that oil drops created and stabilized by tiny NPs are small and possess a considerably lower viscosity than oil drops. Herewith, nanoparticle-stabilized emulsions, owing to their small size, can travel more easily through tiny reservoir rock pores with minimal retention, improved kinetic stability and negligible gravitational separation, resulting in increased oil recovery $[8,23,26,43]$. This profile mechanism (stabilisation of emulsions) probably occurred thanks to the polymer shells, as they temporarily prevented the coalescence of the oil drops. The phase separation of water and oil occurred approximately half an hour in the separator flask; the separated volumes were measured after two days.

The images showed in Figure 8 refers to emulsions generated in-situ by samples NF-A and NF-B; in contrast, samples NF-C and NF-D with the lager particle size generated weak emulsions. Among other factors, this shows that nanoparticles in the aggregate state are weak emulsifying agents. This has been attributed to either the kinetics of particles adsorption to the oil/water interface, being reduced by the presence of aggregated particles or networks, thus hindering the formation of emulsions [44]. 


\subsubsection{Change in Rock Wettability and Surface Roughness}

Nanoparticles target improving oil recovery by changing the surface roughness of the reservoir pores and thus altering its wettability to more water-wet state. The degree of water-wetness that can be achieved largely depend on how the NPs affect the crude oil/brine/rock properties [30]. Presently, we conducted spontaneous imbibition (SI) tests to evaluate such interactions induced by nanoparticles after nanofluid oil recovery experiments. In SI tests, the water will imbibe in the reservoir pores and displace the oil, if the reservoir is likely water-wet, as it has a positive capillary pressure [30]. The results of SI tests are presented in Figure 9. Prior to nano-EOR tests, the cores were aged 7 months in crude oil; post aged core wettability was evaluated by SI using one core plug. The lower curve, in Figure 9, shows the water imbibition performance in the aged core; there was no appreciable oil production before 10 days. Its Amott wettability index was -0.08 , indicating neutral-wet condition. Additional cores aged under similar conditions were used for recovery tests, assuming that they retained the same neutral-wettability. After nanofluid core flood ceased production, the wettability alteration due to the adsorption of NPs was investigated. Figure 9 shows the cumulative oil production by water imbibition as a function of time. Depending on the particle size and particle retention in the pores, rock pore size distribution, etc., varied water imbibition profiles were achieved, but all showed an improved rate of water intake. That is, the water spontaneously invaded the rock pores and displaced the oil significantly, shortly after the placement of the core in the Amott cell. In contrast to the reference core where the oil production by water imbibition occurred from the tenth day, and reached stability 5 days later; thereafter, no oil production was observed. Part of the initial oil production of the aged core was the oil strongly attached to its surface after aging process. The jump in oil recovery, at $120 \mathrm{~h}$, is because the cell was slightly shaken. In Figure 9, cores $\mathrm{H} 2$ and $\mathrm{H} 4$ were treated/injected with samples NF-A and NF-B, respectively. Its imbibition curves indicate superior oil recovery behavior by SI compared to other; this predicts the greater ability of the NPs to change oil-wet pores to water-wet state and increase oil recovery in a timely manner. It is worthy to mention that NF-A and NF-B had the smallest NP size and were stable throughout the duration of nanofluid flooding experiments. Therefore, with small size, NPs could contact most of the pore spaces to change its wettability.

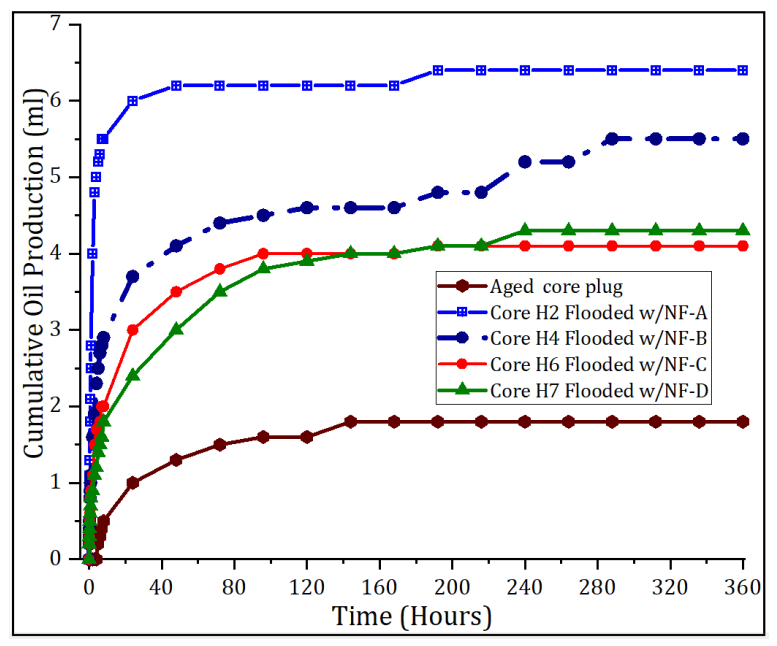

Figure 9. Spontaneous imbibition curves, before and after nanofluid core flooding. 
In Figure 9, we see that greatest recovery of oil occurred within $40 \mathrm{~h}$; after that, a later, an increase in oil recovery was observed. This indicated that the wettability was changed with time, in some parts of the pores, due to the nanoparticles. At equilibrium, the Amott water index $\left(\mathrm{I}_{w}\right)$ was determined and varied from 0.67 to 0.77 . The rate of SI and the $\mathrm{I}_{w}$, both indicate an alteration in core wettability to increasing water-wet condition. The capillary pressure that was negative in oil-wet pores was changed to positive values due to adsorption of NPs, which led to a stronger water imbibition in smallest pores. These results are in line with our previous study [15], and validate the ability of polymer-coated silica nanoparticles to alter the wettability of the rock to favor EOR process.

The mechanism behind the wettability alteration in oil-wet surfaces is still complex. However, it is probably associated with the adsorption of silica NPs to the crude oil/water/rock interfaces due to the attractive forces originating from dipole-dipole interactions $[18,25]$ and structural disjoining pressure. These interactions can develop new surface roughness [23], decrease interfacial energy between the rock surface and the water [25], and destabilise oil films attached on the surface. Consequently, water-wet surfaces are created in the pores and greater capillary pressure ensures greater efficiency in oil recovery by nanoparticles.

\subsubsection{Nanofluid Displacement Pressure}

To better understand the mechanisms of oil recovery by nanofluids, dynamic curves of the pressure difference through the core plugs were recorded and analysed. The premise is that nanofluids can change the flow pattern or the pore volume available for flow; for this, the resulting differential pressure must be greater than the water flood pressure. Under these conditions, mobilization of residual oil can occur through so-called logjamming effect.

Figure 10 shows the change in the flow pattern of the displacement pressure due to nanoparticles. While Figure $10 \mathrm{a}, \mathrm{b}$ exhibit a slight change in water flood pressure, Figure 10c,d show a notable influence of NPs on the displacement pressure. The pair of the cores flooded with NF-B (Figure 10a,b) exhibited an injection pressure pattern similar to that of cores injected with the NF-A sample; the small size and dispersion stability of both samples (NF-A and NF-B) can be the reasons behind the negligible effect on the water flood displacement pressure. Furthermore, it suggests that both NF-A and NF-B samples can propagate through the pores and assist in oil recovery even in the smallest pores. The transport properties of nanoparticles were probably improved by the surface coating materials (polymer molecules), as they can eliminate electrostatic interactions between NPs and oil-wet surfaces [10,11]. The observed pressure profile mechanism during NP injection is consistent with the generation of in-situ emulsions. The propagation of NPs in smaller pores would release the oil from the surface to flow into the water bed and improve the relative permeability to the oil.

In contrast to samples NF-A and NF-B injection, there was a noticeable increase in water injection pressure when nanofluids with the largest particle size (NF-C and NF-D) were injected into the cores. In that case, the pressure gradually increased up to a point; there, it started to fluctuate (see Figure 10c,d). This displacement pressure pattern is a direct evidence of pore channel plugging. The NPs were partially transported through the pores, while others were retained, blocking the pores and forcing injection water to flow through through the bypassed pores. The diversion of water flow can create additional pressure in the adjacent pores; if the pressure is high enough to generate enough capillary numbers, the bypassed oil can be mobilized to the production wells and increase oil recovery. This displacement mechanism has been reported in the literature [28,29], and in most cases controls the oil displacement in water-wet cores $[16,45,46]$.

Figure 6 shows the formation of NP "cake" as a result of aggregation/agglomeration of samples NF-C and NF-D at core inlet. The "nano-cake" is an evidence that the primary blockage occurred at the entrance of the core, followed by filtration of smaller NPs in 
response to the applied displacement pressure. Therefore, this phenomenon can be the main reason for the pressure and may not reflect oil recovery by the log-jamming effect.

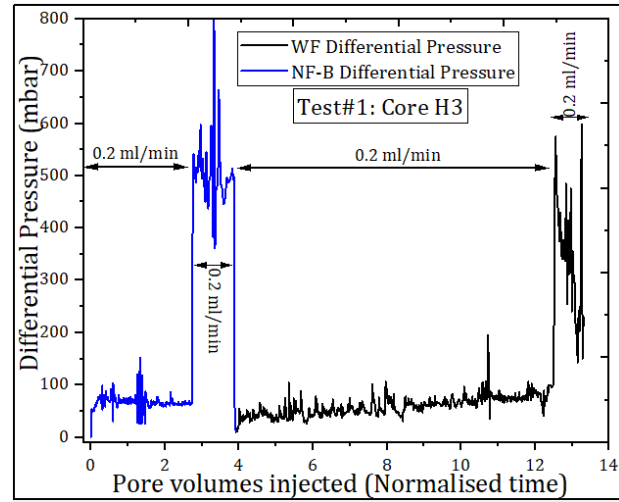

(a)

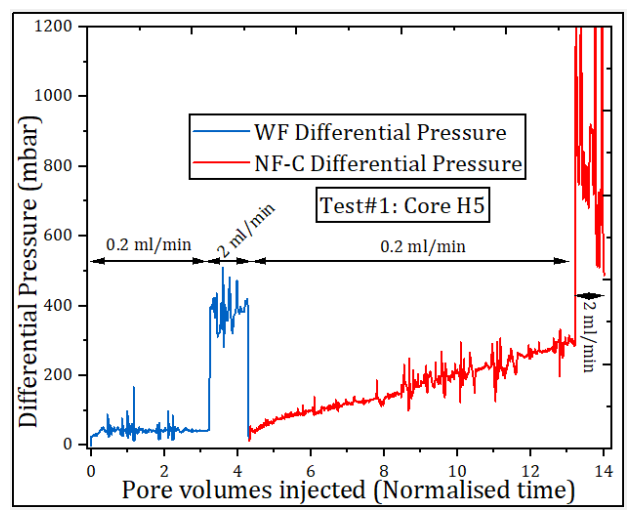

(c)

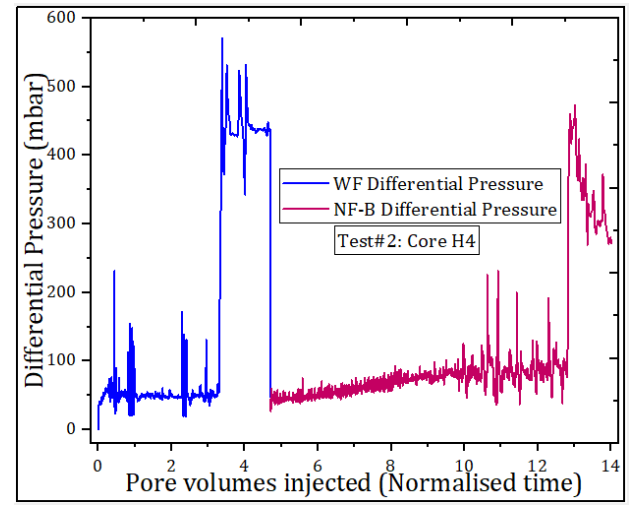

(b)

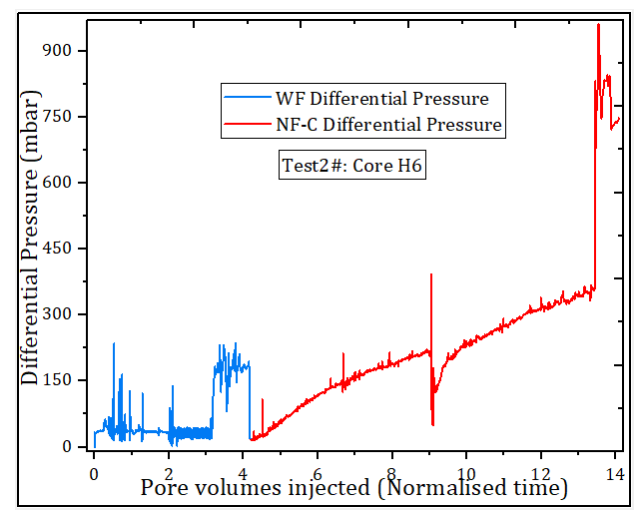

(d)

Figure 10. Pressure profiles for water flood (WF) and nanofluid flood oil recovery. (a) Test \#1: Nanofluid "NF-B" injection showing little effect on water flood pressure; (b) In repeated Test \#2, the pressure shows a slight increase compared to WF pressure; (c) Test \#1, the pressure gradually increases with nanofluid "NF-C" and is higher than WF pressure; and (d) Similar behavior is observed in Test \#2.

Inspecting the magnitude of the pressure increase due to NPs in Figure 10, it seems insufficient for the viscous forces to dominate the displacement process over the capillary forces, therefore, in this work, the flow diversion mechanism cannot fully explain the EOR effect due to the injection of nanoparticles.

\section{Conclusions}

This work presents the results of the influence of polymer-coated silica nanoparticles to enhance oil recovery at harsh reservoir conditions of high temperature and high salinity. This included an investigation of the effect of nanoparticle interactions on the crude oil/water/water interfaces, in order to understand the phenomenon of oil recovery. On the basis of the experimental results, the following conclusions can be drawn:

- Polymer-coated silica nanoparticles have shown a strong ability to increase oil recovery after water flooding. The increment recovery was up to $6 \%$ of OOIP;

- The nanoparticles can reduce the oil/water interfacial tension at a concentration as low as $0.1 \mathrm{wt} . \%$. The smallest nanoparticle size were more efficient in reducing the tension due to the large contact area;

- The flooding experiments indicated that oil was produced as oil-in-water emulsion droplets; these emulsion droplets were stabilized by the nanoparticles. 
- The adsorption of nanoparticles in oil-wet pores can reverse the negative capillary pressure to positive values and change the wettability to water-wet condition;

- The size of nanoparticles and the formation of large aggregates within the pores were observed to increase displacement pressure, resulting in poor oil recovery efficiency;

- Different oil displacement mechanisms, such as reduced IFT, change in wettability, generation of in-situ emulsions and change log-jamming effect can explain the oil recovery phenomenon of polymer-coated silica NPs in intermediate reservoirs. However, the wettability alteration to a more water-wet seemed to govern the oil displacement process.

This paper reveals the potential application of polymer coated silica NPs for oil recovery. Future studies must be directed to improve the stability of the nanoparticles. In addition, studies should also focus on characterizing the charge on the rock surface, the effect of nanoparticles bonding with coating materials (i.e., surface activity and reactivity) to predict their interactions with fluids and rock system during the oil recovery process and probably to determine the contribution of the components involved in the oil recovery process.

Author Contributions: Conceptualization, A.B.; methodology, A.B.; investigation, A.B.; writingoriginal draft preparation, A.B.; writing—review and editing, A.B. and O.T.; supervision, O.T.; project administration, O.T. All authors have read and agreed to the published version of the manuscript.

Funding: This research was funded by the Centre of Studies in Oil and Gas Engineering and Technology, Eduardo Mondlane University, NUIT: 500003545, Maputo-Mozambique, and PoreLab, Centre of Excellence grant number 262644, Trondheim-Norway, and Centre of Studies in Oil and Gas Engineering and Technology, Eduardo Mondlane University (EMU)-Mozambique.

Data Availability Statement: Restrictions apply to the availability of Nanomaterials used in this study. The nanomaterials were obtained from Evonik Industries as research and development products and may be available on request from the company.

Acknowledgments: The authors would like to thank the Research Council of Norway for financial support through PoreLab, Centre of Excellence, project number 262644. Special thanks goes to Evonik Industries for providing the nanoparticles used in this work. Maximilian Cornelius and Ulrich Fischer from Evonik Industries are acknowledged for useful discussions. We thank Eng. Estevão Tivane for the design of the flooding set-up.

Conflicts of Interest: The authors declare no conflict of interest.

\section{References}

1. Sydansk, R.D.; Romero-Zeron, L. Reservoir Conformance Improvement; Society of Petroleum Engineers: Richardson, TX, USA, 2011.

2. Fletcher, A.; Davis, J. How EOR can be transformed by nanotechnology. In Proceedings of the SPE Improved Oil Recovery Symposium, Tulsa, OK, USA, 24-28 April 2010.

3. Bera, A.; Belhaj, H. Application of nanotechnology by means of nanoparticles and nanodispersions in oil recovery-A comprehensive review. J. Nat. Gas Sci. Eng. 2016, 34, 1284-1309. [CrossRef]

4. Das, S.K.; Choi, S.U.; Patel, H.E. Heat transfer in nanofluids-A review. Heat Transf. Eng. 2006, 27, 3-19. [CrossRef]

5. Peng, B.; Zhang, L.; Luo, J.; Wang, P.; Ding, B.; Zeng, M.; Cheng, Z. A review of nanomaterials for nanofluid enhanced oil recovery. RSC Adv. 2017, 7, 32246-32254. [CrossRef]

6. Sandeep, R.; Jain, S.; Agrawal, A. Application of Nanoparticles-Based Technologies in the Oil and Gas Industry. In Nanotechnology for Energy and Environmental Engineering; Springer: Berlin/Heidelberg, Germany, 2020; pp. 257-277.

7. Yu, H.; Kotsmar, C.; Yoon, K.Y.; Ingram, D.R.; Johnston, K.P.; Bryant, S.L.; Huh, C. Transport and retention of aqueous dispersions of paramagnetic nanoparticles in reservoir rocks. In Proceedings of the SPE Improved Oil Recovery Symposium, Tulsa, OK, USA, 24-28 April 2010.

8. ShamsiJazeyi, H.; Miller, C.A.; Wong, M.S.; Tour, J.M.; Verduzco, R. Polymer-coated nanoparticles for enhanced oil recovery. J. Appl. Polym. Sci. 2014, 131. [CrossRef]

9. Gbadamosi, A.O.; Junin, R.; Manan, M.A.; Yekeen, N.; Agi, A.; Oseh, J.O. Recent advances and prospects in polymeric nanofluids application for enhanced oil recovery. J. Ind. Eng. Chem. 2018, 66, 1-19. [CrossRef]

10. Rodriguez, E.; Roberts, M.; Yu, H.; Huh, C.; Bryant, S.L. Enhanced migration of surface-treated nanoparticles in sedimentary rocks. In Proceedings of the SPE Annual Technical Conference and Exhibition, New Orleans, LA, USA, 4-7 October 2009. 
11. Zhang, T.; Murphy, M.J.; Yu, H.; Bagaria, H.G.; Yoon, K.Y.; Nielson, B.M.; Bielawski, C.W.; Johnston, K.P.; Huh, C.; Bryant, S.L. Investigation of nanoparticle adsorption during transport in porous media. SPE J. 2015, 20, 667-677. [CrossRef]

12. Ponnapati, R.; Karazincir, O.; Dao, E.; Ng, R.; Mohanty, K.; Krishnamoorti, R. Polymer-functionalized nanoparticles for improving waterflood sweep efficiency: Characterization and transport properties. Ind. Eng. Chem. Res. 2011, 50, 13030-13036. [CrossRef]

13. Behzadi, A.; Mohammadi, A. Environmentally responsive surface-modified silica nanoparticles for enhanced oil recovery. $J$. Nanopart. Res. 2016, 18, 266. [CrossRef]

14. Choi, S.K.; Son, H.A.; Kim, H.T.; Kim, J.W. Nanofluid Enhanced Oil Recovery Using Hydrophobically Associative Zwitterionic Polymer-Coated Silica Nanoparticles. Energy Fuels 2017, 31, 7777-7782. [CrossRef]

15. Bila, A.; Stensen, J.Å.; Torsæter, O. Experimental Investigation of Polymer-Coated Silica Nanoparticles for Enhanced Oil Recovery. Nanomaterials 2019, 9, 822. [CrossRef] [PubMed]

16. Bila, A.; Åge Stensen, J.; Torsæter, O. Polymer-functionalized silica nanoparticles for improving water flood sweep efficiency in Berea sandstones. E3S Web Conf. 2020, 146, 02001. [CrossRef]

17. Bila, A.; Torsæter, O. Enhancing oil recovery with hydrophilic polymer-coated silica nanoparticles. Energies 2020, 13, 5720. [CrossRef]

18. Roustaei, A.; Moghadasi, J.; Bagherzadeh, H.; Shahrabadi, A. An experimental investigation of polysilicon nanoparticles' recovery efficiencies through changes in interfacial tension and wettability alteration. In Proceedings of the SPE International Oilfield Nanotechnology Conference and Exhibition, Noordwijk, The Netherlands, 12-14 June 2012.

19. Roustaei, A.; Saffarzadeh, S.; Mohammadi, M. An evaluation of modified silica nanoparticles' efficiency in enhancing oil recovery of light and intermediate oil reservoirs. Egypt. J. Pet. 2013, 22, 427-433. [CrossRef]

20. Ding, H.; Zhang, N.; Zhang, Y.; Wei, M.; Bai, B. Experimental Data Analysis of Nanoparticles for Enhanced Oil Recovery. Ind. Eng. Chem. Res. 2019, 58, 12438-12450. [CrossRef]

21. Aziz, H.; Tunio, S.Q. Enhancing oil recovery using nanoparticles-A review. Adv. Nat. Sci. Nanosci. Nanotechnol. 2019, $10,033001$. [CrossRef]

22. Karimi, A.; Fakhroueian, Z.; Bahramian, A.; Pour Khiabani, N.; Darabad, J.B.; Azin, R.; Arya, S. Wettability Alteration in Carbonates using Zirconium Oxide Nanofluids: EOR Implications. Energy Fuels 2012, 26, 1028-1036. [CrossRef]

23. Dai, C.; Wang, X.; Li, Y.; Lv, W.; Zou, C.; Gao, M.; Zhao, M. Spontaneous Imbibition Investigation of Self-Dispersing Silica Nanofluids for Enhanced Oil Recovery in Low-Permeability Cores. Energy Fuels 2017, 31, 2663-2668. [CrossRef]

24. Wasan, D.; Nikolov, A. Spreading of Nanofluids on Solids. Nature 2003, 423, 156-159. [CrossRef]

25. Afolabi, R.O.; Yusuf, E.O. Nanotechnology and global energy demand: challenges and prospects for a paradigm shift in the oil and gas industry. J. Pet. Explor. Prod. Technol. 2019, 9, 1423-1441. [CrossRef]

26. Yakasai, F.; Jaafar, M.Z.; Bandyopadhyay, S.; Agi, A. Current Developments and Future Outlook in Nanofluid Flooding: A Comprehensive Review of Various Parameters Influencing Oil Recovery Mechanisms. J. Ind. Eng. Chem. 2020, 93, 138-162. [CrossRef]

27. Kumar, N.; Gaur, T.; Mandal, A. Characterization of SPN Pickering emulsions for application in enhanced oil recovery. J. Ind. Eng. Chem. 2017, 54, 304-315. [CrossRef]

28. Skauge, T.; Spildo, K.; Skauge, A. Nano-sized particles for EOR. In Proceedings of the SPE improved oil recovery symposium, Tulsa, OK, USA, 24-28 April 2010.

29. Kokubun, M.E.; Radu, F.A.; Keilegavlen, E.; Kumar, K.; Spildo, K. Transport of Polymer Particles in Oil-Water Flow in Porous Media: Enhancing Oil Recovery. Transp. Porous Media 2019, 126, 501-519. [CrossRef]

30. Mohammed, M.; Babadagli, T. Wettability alteration: A comprehensive review of materials/methods and testing the selected ones on heavy-oil containing oil-wet systems. Adv. Colloid Interface Sci. 2015, 220, 54-77. [CrossRef] [PubMed]

31. Miranda, C.R.; Lara, L.S.d.; Tonetto, B.C. Stability and mobility of functionalized silica nanoparticles for enhanced oil recovery applications. In Proceedings of the SPE International Oilfield Nanotechnology Conference and Exhibition, Noordwijk, The Netherlands, 12-14 June 2012. [CrossRef]

32. Khalil, M.; Jan, B.M.; Tong, C.W.; Berawi, M.A. Advanced nanomaterials in oil and gas industry: Design, application and challenges. Appl. Energy 2017, 191, 287-310. [CrossRef]

33. Anderson, W.G. Wettability Literature Survey Part 2: Wettability Measurement. J. Pet. Technol. 1986, 38, 1246-1262. [CrossRef]

34. Ziauddin, M.; Montaron, B.; Hussain, H.; Habashy, T.; Seleznev, N.; Signer, C.; Abdallah, W. Fundamentals of wettability. Schlumberger Oilfield Rev. 2007, 19, 40-67.

35. Eide, Ø.; Fernø, M.; Nybø, S.; Graue, A. Waterflood Stability in SCAL Analysis. In Proceedings of the International Symposium of the Society of Core Analysts, Avignon, France, 8-11 September 2014.

36. Bila, A.L. Experimental Investigation of Surface-Functionalised Silica Nanoparticles for Enhanced Oil Recovery. Ph.D. Thesis, Norwegian University of Science and Technology (NTNU), Trondheim, Norway, 2020.

37. Metin, C.; Bonnecaze, R.; Nguyen, Q. The viscosity of silica nanoparticle dispersions in permeable media. SPE Reserv. Eval. Eng. 2013, 16, 327-332. [CrossRef]

38. Behera, U.S.; Sangwai, J.S. Interaction of Nanoparticles with Reservoir Fluids and Rocks for Enhanced Oil Recovery. In Nanotechnology for Energy and Environmental Engineering; Springer: Berlin/Heidelberg, Germany, 2020; pp. $299-328$.

39. Sheng, J.J. Status of surfactant EOR technology. Petroleum 2015, 1, 97-105. [CrossRef] 
40. Chatzis, I.; Kuntamukkula, M.; Morrow, N. Effect of capillary number on the microstructure of residual oil in strongly water-wet sandstones. SPE Reserv. Eng. 1988, 3, 902-912. [CrossRef]

41. Kim, I.; Worthen, A.J.; Johnston, K.P.; DiCarlo, D.A.; Huh, C. Size-dependent properties of silica nanoparticles for Pickering stabilization of emulsions and foams. J. Nanoparticle Res. 2016, 18, 82. [CrossRef]

42. Arab, D.; Kantzas, A.; Bryant, S.L. Nanoparticle stabilized oil in water emulsions: A critical review. J. Pet. Sci. Eng. 2018, 163, 217-242. [CrossRef]

43. Suleimanov, B.A.; Ismailov, F.; Veliyev, E. Nanofluid for enhanced oil recovery. J. Pet. Sci. Eng. 2011, 78, 431-437. [CrossRef]

44. Binks, B.P.; Whitby, C.P. Nanoparticle silica-stabilised oil-in-water emulsions: improving emulsion stability. Colloids Surfaces Physicochem. Eng. Asp. 2005, 253, 105-115. [CrossRef]

45. Hu, Z.; Azmi, S.M.; Raza, G.; Glover, P.W.J.; Wen, D. Nanoparticle-Assisted Water-Flooding in Berea Sandstones. Energy Fuels 2016, 30, 2791-2804. [CrossRef]

46. Aurand, K.; Dahle, S.; Torsæter, O. Comparison of oil recovery for six nanofluids in Berea sandstone cores. In Proceedings of the International Symposium of the Society of Core Analysts, Avignon, France, 8-11 September 2014; pp. 1-12. 